\title{
Recurrent brief depression - more investigations in clinical samples are now required ${ }^{1}$
}

Classifications of depression based on secondary care samples may have little relevance in primary care settings, where many patients do not fulfil criteria for major depression; for example, through having depressive symptoms that are either too mild or too brief. And yet many such patients receive antidepressant treatments (antidepressants and various psychotherapies). At a time when the appropriate recognition and treatment of people with depressive symptoms is the subject of much discussion, and there is concern about the burgeoning number of new psychiatric diagnoses, the burden and hazards of depressive disorders need to be emphasized. The paper by Pezawas et al. (2003) (in this issue) reports the findings of an epidemiological study in adolescents and young adults, and provides a detailed description of the prevalence and features of one such disruptive disorder, namely recurrent brief depression.

\section{IS RECURRENT BRIEF DEPRESSION A 'NEW' DISORDER?}

Although recurrent brief depression has been described as 'a new subtype of affective disorder' (Angst et al. 1990), it may have a long history: Kraepelin (1921) included short and mild depressive states within the overall category of manic depressive illness. Before the arrival of categorical classificatory schemes, Paskind (1929) had noted that patients with short-lived but recurring depressive episodes were common in primary care settings, and the risk of suicide associated with transient but severe mood disturbance had also been emphasized (Buzzard et al. 1930).

The ground-breaking Research Diagnostic Criteria (Spitzer et al. 1978) included the diagnosis of intermittent depression, but placed it within the category of minor depression, thereby indicating that it was a relatively mild disorder. Based largely on the findings of the pivotal prospective epidemiological study in young adults (the 'Zurich Study') of Angst and colleagues (1984), recurrent brief depression was formally recognized as a distinct form of depressive disorder in the last decade. The International Classification of Diseases (World Health Organization, 1992) includes the category of recurrent brief depressive disorder (ICD-10 F38.10), although the DSM-IV appears less convinced, and only places it within Appendix B - the group of disorders worthy of further investigation (American Psychiatric Association, 1994).

\section{HOW COMMON IS RECURRENT BRIEF DEPRESSION?}

The Zurich Study found that approximately half of those community subjects who had received treatment for depression did not fulfil diagnostic criteria for major depression, through experiencing depressive episodes that were too short-lived (i.e. less than the 2 week cut-off). Around half of these treated subjects experienced brief depressions which occurred approximately monthly, and were associated with significant social and occupational impairment (Angst \& Dobler-Mikola, 1985). By developing operationalized criteria for 'recurrent brief depression' Angst and colleagues were able to show that the disorder had a lifetime prevalence of approximately $10 \%$, similar to that for major depression. Further epidemiological studies have suggested that recurrent brief depression may be a common condition. The point prevalence in the World Health Organization study on Psychological Problems in General Health Care was around 4-6\% (Weiller et al. 1994); the lifetime

${ }^{1}$ Address for correspondence: Dr David S. Baldwin, University Department of Mental Health, Royal South Hants Hospital, Graham Road, Southampton SO14 0YG. 
prevalence in the general population of Sardinia has been estimated to be $6.9 \%$ (Altamura et al. 1995). However, recurrent brief depression had a prevalence of only $2 \%$ in the DSM-IV Mood Disorders Field Trial (Keller et al. 1995). The study reported by Pezawas et al. (2003) indicates that recurrent brief depression has a lifetime prevalence in young adults of $2.6 \%$, and thereby places its prevalence towards the lower end of the range. The true prevalence in the sample may be somewhat higher, as subjects who experienced brief depressive episodes within 1 year of a major depressive episode could not be allocated to the category of recurrent brief depression.

\section{WHAT ARE THE FEATURES IN EPIDEMIOLOGICAL STUDIES?}

As originally defined, the symptoms of recurrent brief depression are essentially similar to those of major depression, being briefer but no less severe (Angst et al. 1990). The findings of the Zurich Study indicated that these two disorders did not differ with respect to age of onset, family history, social class and presentation for treatment, although childhood emotional and behavioural problems were described significantly more often by adults with recurrent brief depression. In the Zurich Study, recurrent brief depression showed similar co-morbidity with somatic disorders, greater co-morbidity with panic disorder, and lesser co-morbidity with dysthymia, than did major depression: whereas the lifetime risk of attempted suicide did not differ significantly between the disorders (Angst \& Hochstrasser, 1994).

A 7 year follow-up study of individuals with recurrent brief depression found considerable fluidity into and out of the condition (Angst \& Hochstrasser, 1994). Of all probands with the disorder between the ages of 20-23 years, 29\% fulfilled the criteria again 7 years later. However, $13 \%$ had developed major depression, $6 \%$ had developed the pattern of both major depression and recurrent brief depression; $53 \%$ had no diagnosis of depression over the 7 years. Follow-up in probands who fulfilled criteria for major depression at the initial assessment showed that $15 \%$ had developed recurrent brief depression, and $8 \%$ experience both major and brief depressive episodes (Angst \& Hochstrasser, 1994).

The study reported by Pezawas et al. (2003) has produced some interesting findings. First, recurrent brief depression did not show the female preponderance typical of major depression (or dysthymia). Secondly, the symptom profile of the two disorders was different: 'classical' depressive symptoms (low mood, loss of interest or pleasure, guilty feelings and suicidal thoughts) were more common in subjects with major depression; only disturbed sleep was significantly more common in recurrent brief depression. Thirdly, the pattern of co-morbidity also differed, recurrent brief depression showing less 1-year co-morbidity with panic disorder, social phobia, generalized anxiety disorder and obsessive-compulsive disorder, and more co-morbidity with post-traumatic stress disorder, than did major depression.

Perhaps the most intriguing finding reported by Pezawas et al. is the lack of an association with attempted suicide in 'combined depression' (i.e. subjects with a lifetime co-occurrence of major depressive disorder and recurrent brief depression). Whereas the Zurich Study showed that people with combined depression had a lifetime attempted suicide rate of $30 \%$ by the age of 28 years (Angst et al. 1990), the Munich Study found that none of those with combined depression had attempted suicide. This may be because the authors included subjects with milder, sub-threshold conditions within the category of combined depression.

\section{WHAT ARE THE FEATURES IN CLINICAL SAMPLES?}

The psychopathological features of patients with recurrent brief depression have not been studied extensively. Prospective investigations in small secondary care samples of highly selected patients in London indicate that brief depressions are of similar severity to major depressive episodes, with a median duration of 3-4 days but an irregular periodicity $(95 \%$ occurring more frequently than every 8 weeks, but only $66 \%$ showing a monthly recurrence) (Montgomery et al. 1990).

The results of prospective studies in out-patients, with regular assessment of depressive symptoms, suggest that there is little co-morbidity with dysthymia or bipolar disorder. Patients with 
recurrent brief depression experience depressive symptoms only intermittently (only $15-20 \%$ of the duration of follow-up) and therefore cannot fulfil criteria for dysthymia; similarly only $3 \%$ of patients experience brief hypomanic episodes (Montgomery et al. 1990). Suicide attempts appear common, especially in the group with combined depression, although this may result from referral bias. There is no clear link to the menstrual cycle in women, in either epidemiological or clinical samples.

Little is known about the degree of overlap between recurrent brief depression and forms of personality disorder, such as DSM-IV borderline personality disorder or ICD-10 emotionally unstable character disorder. The affective instability, unpredictability, associated substance misuse and suicidal behaviour of 'recurrent brief depression' can all be understood as maladaptive personality traits, and further investigations are needed.

\section{ARE THERE ANY EVIDENCE-BASED TREATMENTS FOR RECURRENT BRIEF DEPRESSION?}

Epidemiological studies indicate that many people with recurrent brief depression receive treatment, but there are as yet no proven treatments for the disorder. In a double-blind placebo-controlled study of fluoxetine treatment in patients with a history of suicide attempts but without major depression, there was no advantage for the drug in preventing brief depressive episodes or associated deliberate self-harm (Montgomery et al. 1994). The results of placebo-controlled studies with paroxetine in some patients with repeated deliberate self-harm and probable recurrent brief depression are not necessarily applicable to the wider population of patients with the condition (Kocmur et al. 1998; Verkes et al. 1998). In other papers, Pezawas and colleagues have reported beneficial effects with fluoxetine, reboxetine and mirtazapine (Pezawas et al. $2002 a$; Stamenkovic et al. 1998, 2001), but placebo-controlled studies are needed before any treatment can be recommended.

\section{CONCLUSION}

The study reported by Pezawas and colleagues (2003) attempted to establish whether recurrent brief depression is sufficiently common and disabling to merit further research. The authors also wished to ascertain whether it is a discrete condition rather than a prodrome or residual feature of another disorder; and to identify risk factors for the condition. Do they succeed in these objectives?

While epidemiological studies have demonstrated that recurrent brief depression is indeed a common condition, associated with significant impairment, and considerable co-morbidity, there is still some uncertainty regarding the degree of association with suicidal behaviour. The absence of suicide attempts in the combined group in this sample contrasts not only with the findings of other epidemiological studies, but also with observations from the prospective investigations in London, and more recent follow-up studies in Viennese patients (Pezawas et al. 2002).

Pezawas and colleagues have certainly helped characterize the features of the condition in a younger community sample than that in the Zurich study, but the presence of recurrent brief depression was not determined at the baseline assessment, and risk factors for later recurrent brief depression are not reported. The study was therefore not able to establish fully whether recurrent brief depression evolves into or from another disorder, and more community studies are needed to establish the fluidity of passage between the different categories of depressive disorder. For the time being, the findings of the Zurich study suggest that recurrent brief depression and major depression show substantial longitudinal overlap.

Clinicians may be disappointed that there are still no proven treatments for what appears a common and disabling condition in community samples. However, evidence-based treatments will undoubtedly only become available after the epidemiology and psychopathological features of recurrent brief depression in primary and secondary care samples have been characterized more fully. 


\section{REFERENCES}

Altamura, A. C., Carta, M. G., Carpinello, B., Piras, A., Maccio, M. V. \& Marcia, L. (1995). Lifetime prevalence of brief recurrent depression (results from a community survey). European Neuropsychopharmacology 5, S99-S102.

American Psychiatric Association (1994). Diagnostic and Statistical Manual of Mental Disorders, 4th edn (DSM-IV). American Psychiatric Association: Washington, DC.

Angst, J. \& Dobler-Mikola, A. (1985). The Zurich Study: a prospective study of depressive, neurotic and psychosomatic syndromes. IV. Recurrent and non-recurrent brief depression. European Archives of Psychiatry and Neurological Sciences 234, 408-416.

Angst, J. \& Hochstrasser, B. (1994). Recurrent brief depression: the Zurich study. Journal of Clinical Psychiatry 55 (Suppl.), S3-S9.

Angst, J., Dobler-Mikola, A. \& Binder, J. (1984). The Zurich Study: a prospective study of depressive, neurotic and psychosomatic syndromes. I. Problem, methodology. European Archives of Psychiatry and Neurological Sciences 234, 13-20.

Angst, J., Merinkangas, K., Scheidegger, P. \& Wicki, W. (1990). Recurrent brief depression: a new subtype of affective disorder. Journal of Affective Disorder 91, 87-98.

Buzzard, E. F., Miller, H. E., Riddoch, G., Yellowlees, H., Reynell, W. R., Boyle, H., Hobhouse, N. \& Strauss, E. B. (1930). Discussion on the diagnosis and treatment of the milder forms of the manic-depressive psychosis. Proceedings of The Royal Society of Medicine 23, 881-895.

Keller, M. B., Klein, D. N., Hirschfeld, R. M. A., Kocsis, J. H., McCullough, J. P., Miller, I., First, M. B., Holzer, C. R. B. III, Keitner, G. I. \& Marin, D. B. (1995). Results of the DSM-IV Mood Disorders Field Trial. American Journal of Psychiatry 152, 843-849.

Kocmur, M., Dernovsek, M. Z. \& Tavcar, R. (1998). Effect of paroxetine on intermittent brief depression episodes and suicide attempts among patients with personality disorders. A double-blind placebo-controlled study. Psychiatria Danubina 10, 283-286.

Kraepelin, E. (1921). Manic depressive insanity and paranoia. In Eighth German Edition of the Textbook of Psychiatry, vols. 3 and 4 (translated by M. Barclay). E. \& S. Livingstone: Edinburgh.

Montgomery, D. B., Roberts, A., Green, M., Bullock, T., Baldwin, D. \& Montgomery, S. A. (1994). Lack of efficacy of fluoxetine in recurrent brief depression and suicidal attempts. European Archives of Psychiatry and Clinical Neuroscience 244, 211-215.

Montgomery, S. A., Montgomery, D. B., Baldwin, D. \& Green, M. (1990). The duration, nature and recurrence rate of brief depressions. Progress in Neuropsychopharmacology and Biological Psychiatry 14, 729-735.

Paskind, H. A. (1929). Brief attacks of manic-depressive depression. Archives of Neurology and Psychiatry (Chicago) 22, 123-134.

Pezawas, L., Stamenkovic, M., Aschauer, H. \& Kasper, S. (2002a). Successful treatment of recurrent brief depression (RBD) with reboxetine - a single case analysis. Pharmacopsychiatry 35, 75-76.

Pezawas, L., Stamenkovic, M., Jagsch, R., Ackerl, S., Putz, C., Stelzer, B., Moffat, R., Schindler, S., Aschauer, H. \& Kasper, S. $(2002 b)$. A longitudinal view of triggers and thresholds of suicidal behaviour in depression. Journal of Clinical Psychiatry 63, 866-873.

Pezawas, L., Wittchen, H.-U., Pfister, H., Angst, J., Lieb, R. \& Kasper, S. (2003). Recurrent brief depressive disorder reinvestigated: a community sample of adolescents and young adults. Psychological Medicine 33, 407-418.

Spitzer, R. L., Endicott, J. \& Robins, E. (1978). Research Diagnostic Criteria: rationale and reliability. Archives of General Psychiatry 53, 731-785.

Stamenkovic, M., Pezawas, L., De Zwaan, M., Aschauer, H. N. \& Kasper, S. (1998). Mirtazapine in recurrent brief depression. International Clinical Psychopharmacology 13, 39-40.

Stamenkovic, M., Blasbichler, T., Riederer, F., Pezawas, L., Brandstatter, N., Aschauer, H. N. \& Kasper, S. (2001). Fluoxetine treatment in patients with recurrent brief depression (RBD). International Clinical Psychopharmacology 16, 221-226.

Verkes, R. J., Van der Mast, R. C., Hengeveld, M. W., Tuyl, J. P., Zwinderman, A. H. \& Van Kempen, G. M. J. (1998). Reduction by paroxetine of suicidal behaviour in patients with repeated suicide attempts but not major depression. American Journal of Psychiatry 155, 543-547.

Weiller, E., Boyer, P., Lepine, J. P. \& Lecrubier, Y. (1994). Prevalence of recurrent brief depression in primary care. European Archives of Psychiatry and Clinical Neuroscience 244, $174-181$.

World Health Organization (1992). The ICD-10 Classification of Mental and Behavioural Disorders. Clinical Descriptions and Diagnostic Guidelines. World Health Organization: Geneva. 